\title{
Simulation of bubbling fluidized bed of fine particles using CFD
}

\author{
Jimin Kim and Gui Young Han *, \\ Chemical Process Technology Lab, SK Corporation, Daejeon 305-712, Korea \\ *Department of Chem. Eng., Sungkyunkwan University, Suwon 440-746, Korea \\ (Received 15 July $2006 \cdot$ accepted 7 November 2006)
}

\begin{abstract}
Computational fluid dynamics (CFD) simulation for bubbling fluidized bed of fine particles was carried out. The reliability and accuracy of CFD simulation was investigated by comparison with experimental data. The experimental facility of the fluidized bed was $6 \mathrm{~cm}$ in diameter and $70 \mathrm{~cm}$ in height and an agitator of pitched-blade turbine type was installed to prevent severe agglomeration of fine particles. Phosphor particles were employed as the bed material. Particle size was $22 \mu \mathrm{m}$ and particle density was $3,938 \mathrm{~kg} / \mathrm{m}^{3}$. CFD simulation was carried by two-fluid module which was composed of viscosity input model and fan model. CFD simulation and experiment were carried out by changing the fluidizing gas velocity and agitation velocity. The results showed that CFD simulation results in this study showed good agreement with experimental data. From results of CFD simulation, it was observed that the agitation prevents agglomeration of fine particles in a fluidized bed.
\end{abstract}

Key words: Fluidized Bed, CFD, Fine Particle, Agglomeration

\section{INTRODUCTION}

Flow processes and performance of industrial chemical multiphase reactors very often depend on the geometrical design. To ensure and predict optimum behavior of reactors, a simulation tool should be capable of coupling a mathematical reactor model to the geometrical layout [1].

In the late $1970 \mathrm{~s}$, the development and availability of new high speed computers and new computational techniques made it possible to solve the basic Navier-Stokes equation numerically [1,2]. Arastoopour and Gidaspow [3] analyzed solid flow in a circulating fluidized bed by 1-dimension. Tsuo and Gidaspow [4] also modeled the fluidized bed with solid viscosity and two-phase flow at the riser. Gidaspow [5] studied modeling of conservative equations for gassolid flow. And applications of CFD to fluidized beds were made: erosion [6,7], chemical reaction and heat transfer [8-10] and so on.

Recently, CFD in multiphase flow has become an accepted and useful tool in modeling of gas-solid flow systems [2]. It has also emerged as a new tool for modeling of fluidization, as seen from recent conferences (NICHE, 2000; FLUIDIZATION, 1998; CFD in Reaction Engineering, 2000) [11]. In general, experiments can be costly and time-consuming, especially if a variety of flow conditions and geometric variations are to be considered. With the convenience of increasingly faster digital computers and the efficient implementation of accurate numerical algorithms, CFD is a valuable tool for quickly extracting accurate information about laminar flow and mixing in industrially relevant devices whose complex geometries would have prevented modeling just a few years ago [12]. Recently, in the chemical engineering, CFD has been applied to various study divisions as chemical reactors, packed beds [13], mixers [12], crystallizing equipment, biological systems and so on.

CFD simulation of fluidization was classified by three types. The

To whom correspondence should be addressed.

E-mail: gyhan@skku.ac.kr first type is viscosity input model. Anderson et al. [14] used it for a bubbling bed. Tsuo and Gidaspow [4], Sun and Gidaspow [15] and, Benyahia et al. [16] simulated the riser of a circulating fluidized bed by viscosity input model. The second type is kinetic-theorybased model. Gidaspow [17], who first proposed this model, assumed the particle as gas and applied various equations of gas to particle. These equations are shown in Table 1. Sinclair and Jackson [18] estimated core-annular regime in a circulating fluidized bed by a kinetic-theory-based model. The third type is the K-Epsilon model. Commercial CFD code used this model which is composed of $\mathrm{K}$ of the granular temperature equation and epsilon of the conservation law. The K-Epsilon model is applied to analyze for turbulence in single-phase flow $[19,20]$. However, the K-Epsilon model is not proper for fluidized bed modeling because particle interaction is neglected in this model [2].

In this study, we used the CFD-ACE program (CFDRC Company) as CFD simulation. The simulated CFD results were compared with experimental data and the reliability and the accuracy of CFD simulation was discussed.

\section{EXPERIMENTAL}

A schematic diagram of the experimental facility is shown in Fig. 1. The fluidized bed column of a $6 \mathrm{~cm}$ I.D. $\times 70 \mathrm{~cm}$ long was made of acrylic pipe, and four pressure taps were mounted along its axial height. The pressure tap at the bottom of the bed was located $2 \mathrm{~cm}$ above the distributor and the interval of pressure taps in bottom and top regions was $5 \mathrm{~cm}$, and the interval of pressure taps in middle was $8 \mathrm{~cm}$, respectively. Three pressure transducers were connected to pressure taps and output voltage signals were stored by a personal computer through the data acquisition unit. The number of each sampling per channel was 6000 . In analyzing the pressure fluctuation, the number of used data was 1000 . Agitator had four blades and its shape was pitched-blade turbine, as shown in Fig. 2, and the agitation velocity was controlled by digital controller. Gener- 
Table 1. Ideal gas law for gases, powders and conservations

\begin{tabular}{|c|c|c|}
\hline Molecular & Granular Powder & \\
\hline Definition of thermal temperature $\mathrm{T}$ : & Definition of granular temperature $\Theta$ : & \\
\hline $\mathrm{k}_{B} \mathrm{~T}=\frac{1}{3} \mathrm{~m}\left\langle\mathrm{C}^{2}\right\rangle$ & $\Theta=\frac{1}{3}\left\langle C^{2}\right\rangle$ & (4) \\
\hline $\begin{array}{l}\text { where the Boltzmann constant } \mathrm{k}_{B} \text { converts kinetic } \\
\text { energy into temperature: }\end{array}$ & Where the 3 is due to motion in three directions. & \\
\hline $\mathrm{k}_{B}=1.3805 \times 10^{-23} \mathrm{~J} / \mathrm{K}$ & $\begin{array}{l}\text { To convert from } \mathrm{T} \text { to } \Theta \text {, set } \mathrm{k}_{B} / \mathrm{m}=1 \text { in standard kinetic } \\
\text { theory formulas. }\end{array}$ & \\
\hline Definition of hydrostatic pressure P: & Definition of particulate pressure $\mathrm{P}$ : & \\
\hline $\mathrm{P}=\frac{1}{3} \rho\left\langle\mathrm{C}^{2}\right\rangle$ & $\mathbf{P}=\frac{1}{3} \rho\left\langle\mathbf{C}^{2}\right\rangle$ & $(5)$ \\
\hline where $\rho=\mathrm{nm}$ & $\begin{array}{l}\text { where } \rho \text {, the bulk density, is } \rho=\varepsilon_{s} \rho_{s} \text { and the } 1 / 3 \text { is due to } \\
\text { isotropy and } \mathrm{P}_{x x}+\mathrm{P}_{y y}+\mathrm{P}_{z z}=\rho<\mathrm{C}^{2}>\end{array}$ & \\
\hline Ideal gas law & Particulate ideal state equation & \\
\hline $\mathrm{p}=\mathrm{nk}_{B} \mathrm{~T}$ & $\mathrm{p}=\varepsilon_{s} \rho_{s} \Theta$ & $(6)$ \\
\hline $\begin{array}{l}\text { The internal energy per unit molecule of } \\
\text { the gas }\end{array}$ & Powder Internal Energy & \\
\hline $\mathrm{n}\langle\mathrm{U}\rangle=\frac{3}{2} \mathrm{nk}_{B} \mathrm{~T}$ & $\langle\mathrm{U}\rangle=\frac{3}{2} \mathrm{~m} \Theta$ & $(7)$ \\
\hline
\end{tabular}

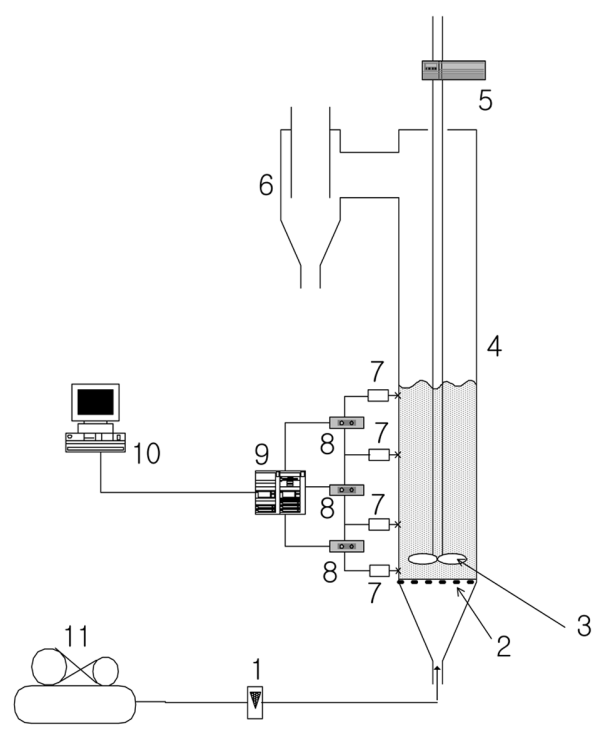

Fig. 1. Schematic diagram of experimental facility for fluidized bed with agitator.

1. Flow meter

2. Gas distributer

3. Impeller

4. Fluidized bed reactor

5. Digital stirrer

6. Cyclone

7. Pressur tap \& filter

8. Pressure transducer

9. Data acquisition

10. Computer

11. Compressor

ally, agglomeration of fine particles was prominent at the bottom bed [21]; the agitator was located at $4 \mathrm{~cm}$ above the gas distributor.

Phosphor particles were employed as the bed material. Average particle size was $22 \mu \mathrm{m}$ and particle density was $3,938 \mathrm{~kg} / \mathrm{m}^{3}$ and this particle was classified as Geldart $\mathrm{C}$ group. In this experiment, initial bed height was $20 \mathrm{~cm}$ from the gas distributor. The average particle size was determined by the size distributor (HIAC Royco,

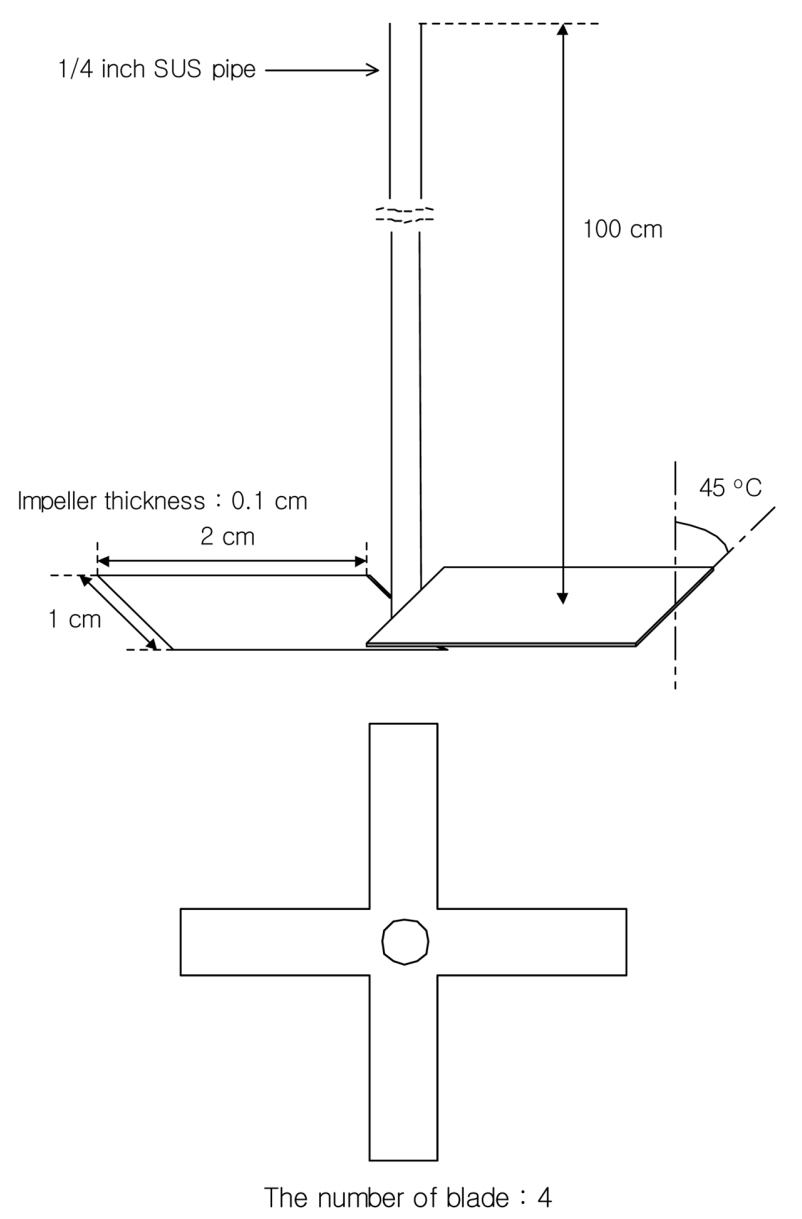

Fig. 2. Shape and size of agitator.

Model 9703), and the cumulative mass fraction with particle size is shown in Fig. 3. Air was used as fluidizing gas. The minimum flui- 


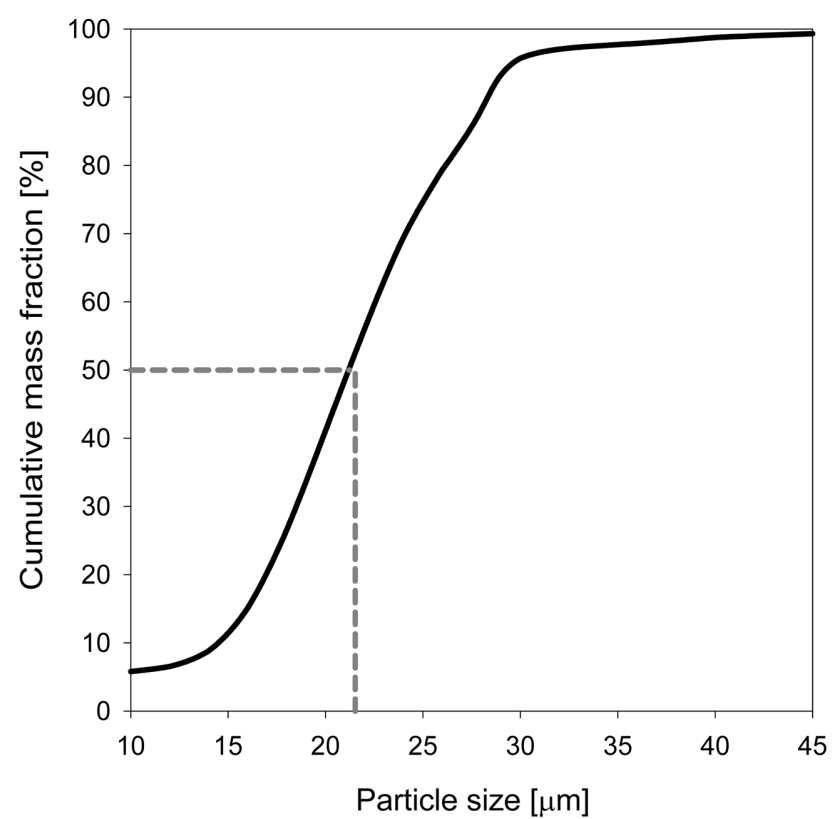

Fig. 3. Cumulative mass fraction with particle size for employed particle.

dizing velocity was calculated as $0.24 \mathrm{~cm} / \mathrm{sec}$ by Ergun's equation as shown in Eq. (1). In calculation of Eq. (1), the value of $\varepsilon_{m f}$ was 0.55 , which was obtained by experiment, and sphericity was assumed as 1.0.

$$
150 \frac{\left(1-\varepsilon_{m f}\right)^{2}}{\varepsilon_{m f}^{3}} \frac{\mu_{g} \mathrm{U}_{m f}}{\phi^{2} \mathrm{~d}_{p}^{2}}+1.75 \frac{1-\varepsilon_{m}}{\varepsilon_{m f}^{3}} \frac{\rho_{g} \mathrm{U}_{m f}^{2}}{\phi^{2} \mathrm{~d}_{p}}=\left(1-\varepsilon_{m f}\right)\left(\rho_{p}-\rho_{g}\right) \mathrm{g}
$$

The experiment was carried at room temperature and atmospheric pressure. A sampling rate of $100 \mathrm{~Hz}$ was determined in this study to obtain the pressure drop fluctuation signals.

During the CFD simulation with the Unix system, a cylinder grid was made with $6 \mathrm{~cm}$ inside diameter and $70 \mathrm{~cm}$ height, the same dimension as the experimental facility. Grid volume was separated by loaded particle height to equal experimental condition. In the loaded particle region, particle distribution was greater than other region during fluidization. Therefore, grid section for loaded particle was composed of 2401 cells to get accurate simulation. The other grid section was composed of 931 cells. The grid was made cylinder type because the height of the fluidized bed reactor was sufficiently much higher than a fluidized bed. Therefore, a cyclone did not affect the fluidizing gas velocity. As in this study, Gidaspow [17] excluded the effect of a cyclone in numerical analysis for a bubbling fluidized bed. Input values, which were physical properties of the employed particles, were $22 \mu \mathrm{m}$ mean particle diameter and $3,938 \mathrm{~kg} / \mathrm{m}^{3}$ particle density in CFD simulation. The viscosity input model was employed in this study and the particle viscosity, which is an important variable in fluidized bed simulation, was used $0.1091 \mathrm{~kg} / \mathrm{m} \cdot \mathrm{s}$ by equation of Gidaspow [17]. Lyczkowski et al. [22] and Anderson et al. [14] stated that the viscosity input model was favorably applied to simulate for bubble and flow patterns in a bubbling fluidized bed.

In this simulation, a two-fluid module was used, which is within the CFD-ACE program because fluidization was solid-gas flow.
Two-fluid module uses the viscosity input model. CFD simulation was carried by transient mode because particles always move in a fluidized bed. For the fully developed state of fluidization, the result of simulation was obtained at $10 \mathrm{sec}$ when the time step was 0.01 sec. Therefore, the result at $10 \mathrm{sec}$ was the $10,000^{\text {th }}$ simulated result. At this time, convergence was 0.001 and minimum residual was $1 \times 10^{-18}$. In fact, nearly constant values of pressure drop, particle velocity, fluidizing gas velocity and void fraction were observed after 5 second sof start of fluidization. Ding and Gidaspow [23] used the result at $2.0 \mathrm{sec}, \mathrm{Xu}$ and $\mathrm{Yu}$ [24] used the result at $7.44 \mathrm{sec}$ and Pain et al. [25] used the result at $3.82 \mathrm{sec}$ for bubbling bed simulation. Therefore, the result at $10 \mathrm{sec}$ in this study was enough for fully developed state of fluidization.

Simulation for fluidizing flow behavior and void fraction was carried out with fluidizing gas velocity from $2.46 \mathrm{U}_{g} / \mathrm{U}_{m f}$ to $8.59 \mathrm{U}_{g} /$ $\mathrm{U}_{m f}$. Simulation for effect of agitation was also carried out by fan model. Input values for the fan model were the same dimension of size and angle of blade in the experimental facility.

To compare the result of simulation with experimental data, solid fractions were obtained at 35 points with bed height and bed radius from simulation. The calculated solid fractions were compared with experimental data, and the agreement of simulation results with experimental data was discussed.

\section{RESULTS AND DISCUSSION}

The minimum fluidizing velocity was experimentally determined and Fig. 4 shows that minimum fluidizing velocity $\left(\mathrm{U}_{m f}\right)$ was about $0.5 \mathrm{~cm} / \mathrm{sec}$. However, minimum fluidizing gas velocity calculated based on Ergun equation was $0.24 \mathrm{~cm} / \mathrm{sec}$, which means that the difference of minimum fluidizing velocity is due to the change of effective particle diameter. Because of particle-particle interaction (electrostatic, van der Waals force), fine particles are easily agglomerated and the effective particle size for fluidization becomes big-

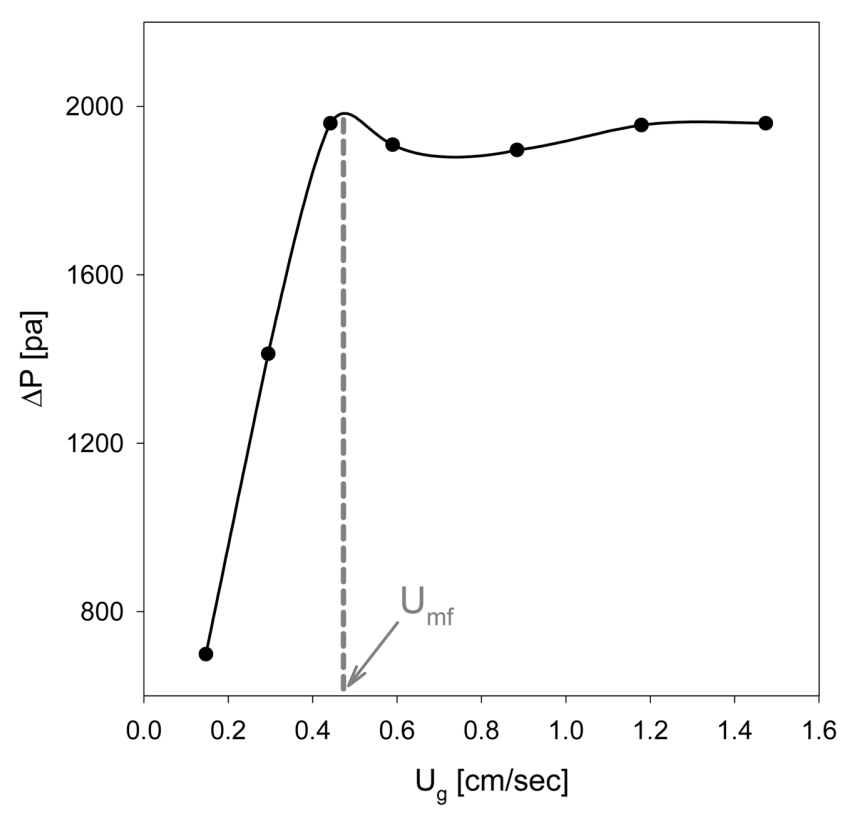

Fig. 4. Experimental measurement of minimum fluidizing velocity. 
ger. Therefore, it can be said that the employed phosphor particle has strong cohesive force. This strong agglomeration characteristic appears for Geldart's group C particles.

In this study, two-fluid modules were used. To use two-fluid modules, simulation was carried by viscosity input model which has constant value of fluidizing gas viscosity and particle viscosity. During the CFD simulation of a fluidized bed, particle viscosity was an important variable $[1,4]$ and to determine the particle viscosity, the kinetic theory of multiphase flow which was proposed by Gidaspow [17] was employed. This theory was composed with Eqs. (2) and (3).

$$
\begin{aligned}
& \mu_{s}=\frac{5 \sqrt{\pi}}{48(1+\mathrm{e}) \mathrm{g}_{0}} \rho_{p} \mathrm{~d}_{p} \Theta^{1 / 2}\left[1+\frac{4}{5}(1+\mathrm{e}) \mathrm{g}_{0} \varepsilon_{s}\right]^{2}+\frac{4}{5} \varepsilon_{s}^{2} \rho_{p} \mathrm{~d}_{p} \mathrm{~g}_{0}(1+\mathrm{e})\left(\frac{\Theta}{\pi}\right)^{1 / 2} \\
& \mathrm{~g}_{0}=\frac{3}{5}\left[1-\left(\frac{\varepsilon_{s}}{\varepsilon_{s, \text { max }}}\right)^{1 / 3}\right]^{-1}
\end{aligned}
$$

The coefficient of restitution, e, in Eq. (2) was assumed as 0.8, as proposed by Savage [26]. Gidaspow [17] used 0.8 as coefficient of restitution for simulation of a bubbling bed. Granular temperature was obtained by Eqs. (4)-(6) in Table 1. Maximum solid volume fraction was $0.7405(=\pi / 3 \sqrt{2})$ because particles were supposed
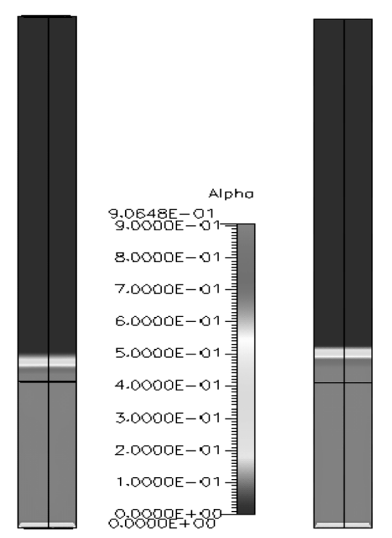

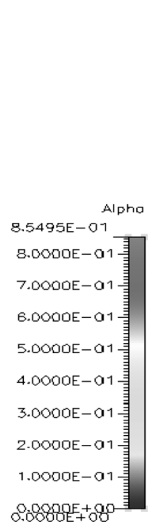

(b)
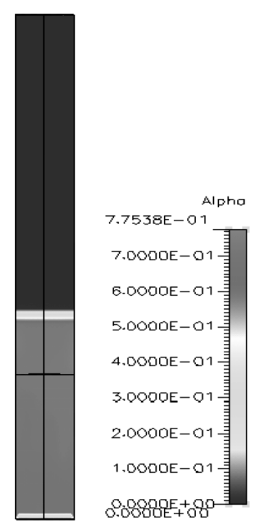

(e)
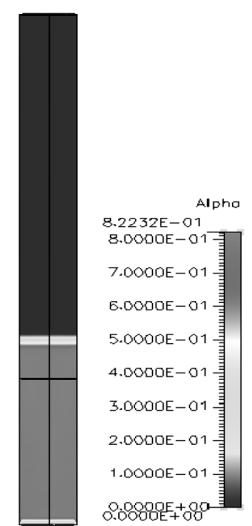

(c)
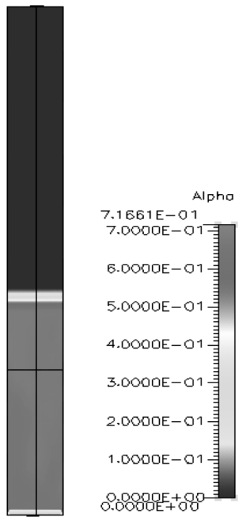

(f) to be perfect spheres and Gidaspow [17] used this supposition.

The dependence of bed height and solid fraction on the different fluidizing gas velocity in this CFD simulation is shown in Fig. 5. In Fig. 5, approximately 60 percent of alpha is solid volume fraction because in CFD simulation alpha is assumed as 1.0 in packed beds. As shown in Fig. 5, bed height is increased with fluidizing gas velocity and this flow behavior is general in a fluidized bed. Therefore, the general flow behavior of fluidization is confirmed simply by CFD simulation.

Particle velocity and flow field are shown in Fig. 6 and the W2 is denoted as the particle velocity along bed height. Plus $(+)$ and minus (-) values of W2 in Fig. 6 mean the direction of particle flow in the fluidized bed. If W2 takes a minus value, particle flow is toward the gas distributor. As shown in Fig. 6, particle flow becomes turbulent, which is uneven movement at planes of symmetry, above $\mathrm{U}_{g} / \mathrm{U}_{m f}=6.14$. In general, particle flow become turbulent as the fluidizing gas velocity is increased in a fluidized bed. In Fig. 6, this general flow pattern of particles in a fluidized bed was confirmed by CFD simulation. However, the expected flow pattern of channeling and agglomeration, which generally occurs in a fine particle

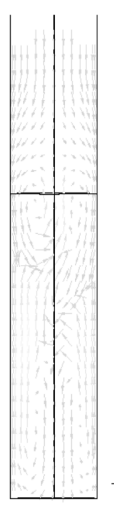

(a)

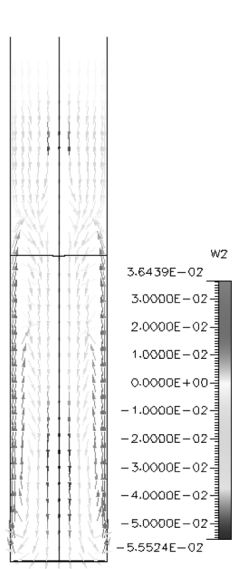

(b)

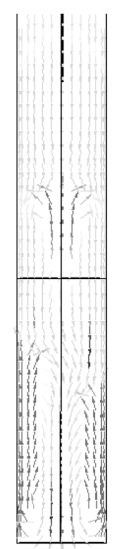

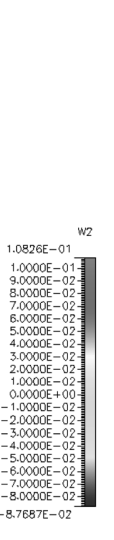

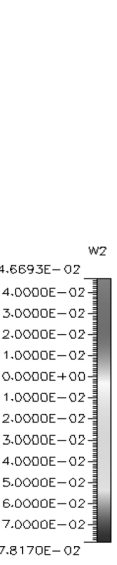

(d)

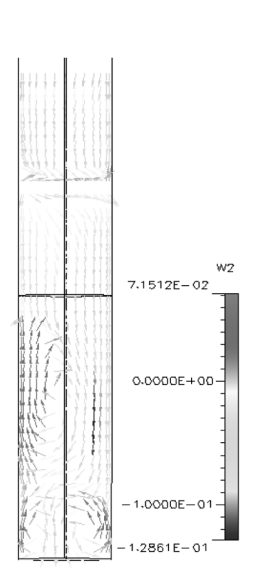

(e)

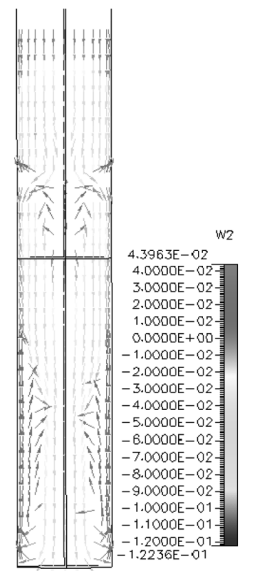

(c)

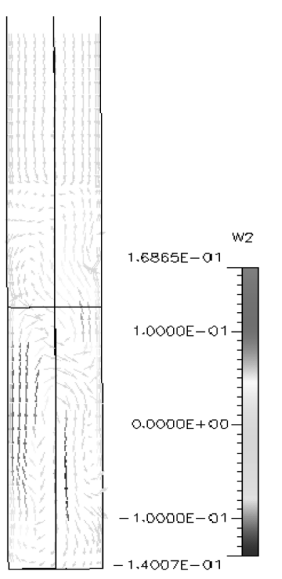

(f)

Fig. 5. Solid volume fraction and bed height for different fluidizing gas velocity as a CFD result ((a) $\mathrm{U}_{g} / \mathrm{U}_{m f}=2.46$, (b) $\mathrm{U}_{g} /$ $\mathbf{U}_{m f}=3.68$, (c) $\mathbf{U}_{g} / \mathbf{U}_{m f}=4.91$, (d) $\mathbf{U}_{g} / \mathbf{U}_{m f}=6.14$, (e) $\mathbf{U}_{g} / \mathbf{U}_{m f}=7.37$, (f) $\mathrm{U}_{g} / \mathrm{U}_{m f}=8.59$ ).

Fig. 6. Solid velocity and flow profile for different fluidizing gas velocity as a CFD result ((a) $\mathrm{U}_{g} / \mathrm{U}_{m f}=2.46$, (b) $\mathrm{U}_{g} / \mathrm{U}_{m f}=3.68$, (c) $\mathbf{U}_{g} / \mathbf{U}_{m f}=4.91$, (d) $\mathbf{U}_{g} / \mathbf{U}_{m f}=6.14$, (e) $\mathbf{U}_{g} / \mathbf{U}_{m f}=7.37$, (f) $\mathbf{U}_{g} / \mathbf{U}_{m f}$ $=8.59$ ). 


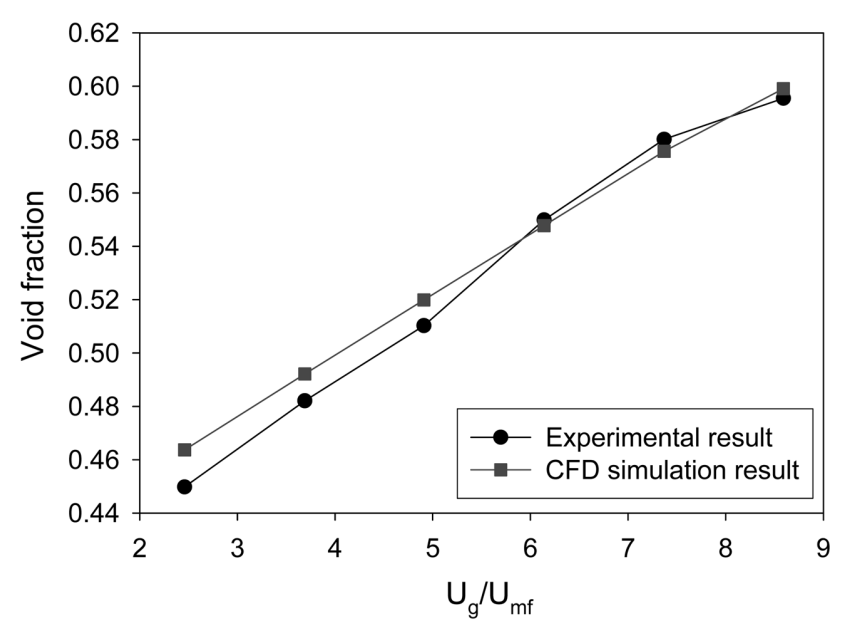

Fig. 7. Comparison of CFD simulation results with experimental results for different fluidizing gas velocity.

fluidized bed, was not confirmed by CFD simulation in this study.

In order to determine the accuracy of CFD simulation, the calculated void fraction by CFD simulation was compared with experimental data and Fig. 7 shows the comparison of the data. As shown in Fig. 7, the result of CFD simulation was similar to experimental data. However, the calculated values of CFD simulation were a little bit higher than experimental data when fluidizing gas velocity was at a relatively low range $\left(\mathrm{U}_{g} / \mathrm{U}_{m f}=2-6\right)$. It is believed that at a low gas velocity the agglomeration of fine particles is more severe than at the higher gas velocity and the agglomeration of fine particles caused an increase of effective particle size. Therefore, the calculated void fraction was higher at the low gas velocity ranges and the difference became closer at the higher gas velocity.

In order to simulate the effect of agitation velocity, a fan model was used. Generally, a fan model was used to simulate flow patterns in a batch reactor. In this fluidized bed system, the effect of agitation velocity was simulated with agitation velocity at $\mathrm{U}_{g} / \mathrm{U}_{m f}=$ 3.68. During the fan model simulation, solid velocity, gas velocity and solid volume fraction were the same values with different agita-

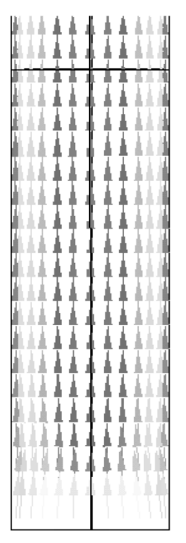

(a)

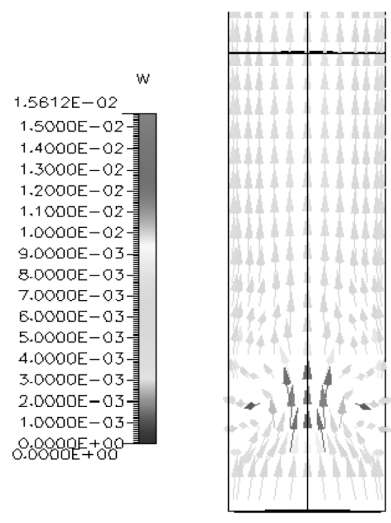

(b)
Fig. 8. Gas velocity and flow profile as CFD result (a) without fan model and (b) with fan model. tion velocity. To check the reliability of this fan model, simulation was carried without particles and the result is shown in Fig. 8. As shown there, the flow pattern and the gas velocity were changed with fan model. Therefore, it was concluded from this model that the agitation velocity does not change particle flow but prevents increasing of effective particle size and agglomeration. Mawatari et al. [27] predicted agglomeration of fine particles by Ergun's equation at minimum fluidizing gas velocity with $6 \mu \mathrm{m}$ and $10 \mu \mathrm{m}$ particles. They found that effective particle size was decreased with the action of vibration. Therefore, it was concluded that the preventing agglomeration by vibration or agitation caused the decrease in the effective particle size and increased the bed height and void fraction, thus increasing smooth fluidization. Malhotra et al. [28] and Park et al. [29] also reported similar results.

\section{CONCLUSION}

CFD simulation in a bubbling fluidized bed of fine particles was carried out. The reliability and accuracy of CFD simulation results was investigated by comparing with experimental data. The experimental facility of fluidized bed was $6 \mathrm{~cm}$ in diameter and $70 \mathrm{~cm}$ in height and an agitator of pitched-blade turbine type was installed to find out the effect of agitation on the flow behavior of fine particles in a bubbling fluidized bed. CFD simulation was carried by two-fluid module which was composed of a viscosity input model and fan model. CFD simulation and experiment were carried out by changing the fluidizing gas velocity and agitation velocity. From the results of CFD simulation, it was observed that mechanical agitation prevents agglomeration of fine particles in a fluidized bed and thus decreases the effective particle diameter and increases the void fraction. This study also provided the possibility of application of CFD simulation to the fluidized bed of fine particles.

\section{ACKNOWLEDGMENT}

This work was supported by grant No. R01-2004-000-10028-0 from the Basic Research Program of the Korea Science and Engineering Foundation.

\section{NOMENCLATURES}

C : particle concentration $\left[\mathrm{Pa} \cdot \mathrm{m}^{3} / \mathrm{kg}\right]$

$\mathrm{d}_{p} \quad$ : particle size $[\mu \mathrm{m}]$

e : coefficient of restitution [-]

g : gravity force $\left[\mathrm{m} / \mathrm{sec}^{2}\right]$

$\mathrm{g}_{0} \quad$ : radial distribution function

$\mathrm{U}_{g} \quad$ : superficial fluidizing gas velocity $[\mathrm{m} / \mathrm{sec}]$

$\mathrm{U}_{m f}$ : minimum fluidizing velocity [m/sec]

\section{Greek Letters}

$\rho_{p} \quad:$ particle density $\left[\mathrm{kg} / \mathrm{m}^{3}\right]$

$\rho_{g} \quad:$ gas density $\left[\mathrm{kg} / \mathrm{m}^{3}\right]$

$\varepsilon_{m f} \quad$ : void fraction in minimum fluidizing conditions [-]

$\varepsilon_{s} \quad$ : solid volume fraction [-]

$\varepsilon_{s \text { max }}:$ maximum solid volume fraction [-]

$\mu_{g} \quad$ : viscosity of gas $[\mathrm{kg} / \mathrm{m} \cdot \mathrm{s}]$

$\mu_{s}$ : solid phase shear viscosity [cP] 
$\Theta \quad$ : granular temperature $\left[\mathrm{kg} / \mathrm{m}^{3}\right]$

$\phi \quad$ : sphericity of particle [-]

\section{REFERENCES}

1. A. Samuelsberg and B. H. Hjertager, AIChE J., 42, 1536 (1996).

2. V. Mathiesen, T. Solberg, H. Arastoopour and B. Hjertager, AIChE J., 45, 2503 (1998).

3. H. Arastoopour and D. Gidaspow, Powder Technology, 22, 77 (1979).

4. Y. P. Tsuo and D. Gidaspow, AIChE J., 36, 885 (1990).

5. D. Gidaspow, Appl. Mech. Rev., 39(1), 1 (1986).

6. R. W. Lyczkowsky, S. Folga, S. L. Chang, J. X. Bouillard, C. S. Wang, G. F. Berry and D. Gidaspow, Can. Chem. Eng., 67, 465 (1989).

7. J. Ding and R. W. Lyczkowski, Powder Technology, 73, 127 (1992).

8. P. Kostamis, C. W. Richards and N. C. Markatos, PhysicoChem. Hydrody., 9, 219 (1987).

9. K. N. Theologos and N. C. Markatos, Trans. IchemE., 70, Part A, 239 (1992).

10. K. N. Theologos and N. C. Markatos, AIChEJ., 39(6), 1007 (1993).

11. D. Mantonis, D. Gidaspow and M. Bahary, AIChE J., 48(7), 1413 (2002).

12. J. M. Zalc, E. S. Szalai, M. M. Alvarez and F. J. Muzzio, AIChE J., 48(10), 2124 (2002).

13. A. Ortiz-Arroyo, F. Larachi, B. P. A. Grandjean and S. Roy, AIChE J., 48(8), 1596 (2002).
14. K. Anderson, S. Sundaresan and R. Jackson, J. Fluid Mech., 303, 327 (1995).

15. B. Sun and D. Gidaspow, Ind. Eng. Chem. Res., 38, 787 (1999).

16. S. Benyahia, H. Arastoopour and T. Knowlton, Fluidization X, Proc. Engineering Foundation Conf. on Fluidization, L.-S. Fan and T. Knowlton, Eds., New York (1998).

17. D. Gidaspow, Multiphase flow and fluidization: Contimum and kinetic theory descriptions, Academic Press (1994).

18. J. L. Sinclair and R. Jackson, AIChE J., 35, 1473 (1989).

19. S. E. Elghobashi and T. W. Abou-Arab, Phys. Fluids, 26, 931 (1983).

20. C. P. Chen, Can. J. Chem. Eng., 63, 349 (1985).

21. Z. Wang, M. Kwauk and H. Li, Chem. Eng. Sci., 53(3), 377 (1998).

22. R. W. Lyczkowsky, I. K. Gamwo, F. Dobran, H. Ali, B. T. Chao, M. M. Chen and D. Gidaspow, Powder Technology, 76, 65 (1993).

23. J. Ding and D. Gidaspow, AIChE J., 36(4), 523 (1990).

24. B. H. Xu and A. B. Yu, Chem. Eng. Sci., 52(16), 2785 (1997).

25. C. C. Pain, S. Mansoorzadeh, J. L. M. Gomes and C. R. E. de Oliveira, Powder Technology, 128, 56 (2002).

26. S. B. Savaqe, Theory of dispersed multiphase flow, R. E. Meyer, Eds., Academic Press, New York (1983).

27. Y. Mawatari, Y. Tatemoto and K. Noda, Powder Technology, 131, 66 (2003).

28. K. Malhotra, L. Law-Kwet-Cheong and A. S. Mujumdar, Powder Technology, 39, 101 (1984).

29. J. Park, J. Kim, S.-H. Cho, K.-H. Han, C.-K. Yi and G-T. Jin, Korean J. Chem. Eng., 16, 659 (1999). 